\title{
Article \\ Paternal Methyl Donor Supplementation in Rats Improves Fertility, Physiological Outcomes, Gut Microbial Signatures and Epigenetic Markers Altered by High Fat/High Sucrose Diet
}

\author{
Faye Chleilat ${ }^{1}\left(\mathbb{D}\right.$, Alana Schick $^{2}$, Julie M. Deleemans ${ }^{3,4}\left(\mathbb{D}\right.$ and Raylene A. Reimer ${ }^{1,5, *(\mathbb{D}}$ \\ 1 Faculty of Kinesiology, University of Calgary, Calgary, AB T2N 1N4, Canada; fatima.chleilat1@ucalgary.ca \\ 2 International Microbiome Centre, Cumming School of Medicine, University of Calgary, Calgary, AB T2N 4N1, \\ Canada; alana.schick@bcchr.ca \\ 3 Division of Medical Science, Cumming School of Medicine, University of Calgary, Calgary, AB T2N 4N1, \\ Canada; julie.deleemans@ucalgary.ca \\ 4 Division of Psychosocial Oncology, Cumming School of Medicine, University of Calgary, Calgary, \\ AB T2N 4N1, Canada \\ 5 Department of Biochemistry and Molecular Biology, Cumming School of Medicine, University of Calgary, \\ Calgary, AB T2N 4N1, Canada \\ * Correspondence: reimer@ucalgary.ca; Tel.: +1-(403)-220-8218
}

\section{check for}

updates

Citation: Chleilat, F.; Schick, A.; Deleemans, J.M.; Reimer, R.A.

Paternal Methyl Donor

Supplementation in Rats Improves Fertility, Physiological Outcomes, Gut Microbial Signatures and Epigenetic Markers Altered by High Fat/High Sucrose Diet. Int. J. Mol. Sci. 2021, 22, 689. https://doi.org/10.3390/ ijms22020689

Received: 11 December 2020 Accepted: 9 January 2021 Published: 12 January 2021

Publisher's Note: MDPI stays neutral with regard to jurisdictional clai$\mathrm{ms}$ in published maps and institutional affiliations.

Copyright: (C) 2021 by the authors. Licensee MDPI, Basel, Switzerland. This article is an open access article distributed under the terms and conditions of the Creative Commons Attribution (CC BY) license (https:// creativecommons.org/licenses/by/ $4.0 /)$.

\begin{abstract}
Increased consumption of high fat/sucrose (HF/S) diets has contributed to rising rates of obesity and its co-morbidities globally, while also negatively impacting male reproductive health. Our objective was to examine whether adding a methyl donor cocktail to paternal HF/S diet (HF/S+M) improves health status in fathers and offspring. From 3-12 weeks of age, male Sprague Dawley rats consumed a HF/S or HF/S+M diet. Offspring were followed until 16 weeks of age. Body composition, metabolic markers, gut microbiota, DNA methyltransferase (DNMT) and microRNA expression were measured in fathers and offspring. Compared to HF/S, paternal HF/S+M diet reduced fat mass in offspring $(p<0.005)$. HF/S+M fathers consumed $16 \%$ fewer $\mathrm{kcal} /$ day, which persisted in HF/S+M female offspring and was explained in part by changes in serum glucagon-like peptide-1 (GLP-1) and peptide tyrosine tyrosine (PYY) levels. Compared to HF/S, HF/S+M fathers had a 33\% improvement in days until conception and 300\% fewer stillbirths. In fathers, adipose tissue DNMT3a and hepatic miR-34a expression were reduced with HF/S+M. Adult male offspring showed upregulated miR-24, $-33,-122 \mathrm{a}$ and -143 expression while females exhibited downregulated miR-33 expression. Fathers and offspring presented differences in gut microbial signatures. Supplementing a paternal HF/S diet with methyl-donors improved fertility, physiological outcomes, epigenetic and gut microbial signatures intergenerationally.
\end{abstract}

Keywords: paternal nutritional programming; one-carbon metabolism; gut microbiota; DNMT; microRNA; insulin resistance

\section{Introduction}

Growing evidence suggests that the decline in male reproductive fitness globally, is in part due to the growing obesity epidemic [1]. Human [2,3] and animal studies [4] have shown that high fat diets, which often reflect poor nutritional status and contribute to increased body mass index (BMI), have been associated with compromised sperm quality, embryo development and fetal growth. Obesity is characterized by excess adipose tissue as well as the deposition of fat in ectopic locations [5], increased plasma fatty acids and an augmented occurrence of insulin resistance [6]. In murine models, high fat diet-induced hyperglycemia, hyperinsulinemia and hypercholesterolemia are associated with alterations in testicular morphology $[7,8]$. The relationship between male reproductive health and obesity is predictable based on the fact that cholesterol is the chief metabolic precursor 
involved in testosterone synthesis [9] and the principal spermatogenesis regulator [10], both of which are modulated in part by epigenetics.

Epigenetics refers to modifications to DNA that affect gene expression profiles of a cell but occur in the absence of changes to the DNA sequence [11]. In comparison to the genome, there is considerable plasticity at the cellular epigenetic level. Among the most widely studied epigenetic mechanisms are DNA methylation and non-coding RNA expression [12].

Non-coding RNAs (ncRNAs) are made up of long ( $>200$ nucleotides) or small $(<200$ nucleotides) ncRNAs, which function as small housekeeping or regulatory ncRNA, the latter including microRNAs [12]. MicroRNAs (19-25 bp in length) function as mRNA translation suppressors or inducers of mRNA breakdown in mammalian cells [13]. In the liver, miRNAs are postulated to coordinate cell lineage differentiation during organ development, playing a crucial role in lipid metabolism and disease modulation, making them valuable prognostic and therapeutic biomarkers clinically [14].

DNA methylation is largely associated with gene regulation and cell differentiation. The primary targets of methylation are CpG dinucleotides in non-coding regions, like promotors [12]. DNA methylation involves the careful coordination of methylating enzymes known as DNA methyl transferases (DNMTs). DNMTs transfer a methyl group from Sadenosylmethionine (SAM) to a cytosine residue, ultimately forming 5-methylcytosine [12]. The varying types of DNMTs include DNMT3a and $3 \mathrm{~b}$ which control de novo DNA methylation activity and DNMT1, which maintains methylation profiles during DNA replication and cell division [15]. A by-product of the methyltransferase reaction is homocysteine (Hcy) [16]. DNA methylation machinery operate on a myriad of different tissues, most notably, adipocytes, which modulate important adipocyte metabolic functions [17]. Moreover, emerging evidence has postulated that DNA methylation is involved in the transgenerational inheritance of obesity and metabolic syndrome [18].

One carbon metabolism is comprised of the interconnected folate and methionine cycles that facilitate the transfer of 1C moieties required for cellular processes [19]. The key dietary constituents that mediate one carbon metabolism are folate, other $B$ vitamins (B2, B6, and B12), methionine, choline and betaine. Amino acid methionine levels in the body are dependent on dietary intake, protein catabolism and the re-methylation of Hcy [20]. Methionine can be converted into SAM, which functions as a universal methyl donor in most methyltransferase reactions [21]. Vitamin B12 is an important co-factor for methionine synthase, the rate-limiting enzyme that converts Hcy to methionine [22]. It is via Hcy remethylation that the folate cycle and methionine cycle are linked [20]. The primary role of folate is to donate or accept one-carbon units, which it primarily does via tetrahydrofolate [23]. Betaine, which is derived from the oxidation of choline, can also be used as a methyl donor to recycle Hcy to methionine [24]. The availability of methyl groups originating from diet (derived from methyl-folate, methionine or choline/betaine) directly affect DNA and histone methylases via their actions as precursors to SAM, and thereby influence epigenetic modifications [25-29]. Importantly, growing evidence has also emerged for the role of dietary methyl donors to impact gut microbiota composition [20,30,31].

While there is substantial evidence for maternal diet via its effects on one carbon transfer to influence long-term metabolism and disease risk in offspring [32], less is known about paternal diet. A nutritionally poor diet in fathers has been shown to affect cellular one-carbon metabolism by increasing levels of serum and tissue Hcy, which negatively affects male fertility [33]. Moreover, alterations in DNA methylation have been assessed in the sperm of infertile males in human [34] and animal [35] studies, where both showed impaired spermatogenesis, with the rodent model observing this impairment among F3 progeny as well. Interestingly, in sub-fertile men, folate supplementation can improve sperm quality [36].

Previous work showed that maternal diets supplemented with methyl donors attenuate adverse phenotypes in offspring associated with maternal high fat diet intake [37]. To our knowledge, this is the first study to examine whether a paternal diet supplemented 
with a methyl donor cocktail of betaine, choline, folic acid and vitamin B12 attenuates the adverse metabolic outcomes, epigenetic changes and gut microbial effects of a paternal high fat/sucrose diet in offspring.

\section{Results}

\subsection{Paternal HF/S+M Decreases Adiposity in Adult Male and Female Offspring}

In fathers, no difference in body weight (Figure 1A), body composition (Table 1) or relative organ weights was observed (Table 2) between HF/S and HF/S+M groups. From 4 weeks of age until euthanasia, offspring exhibited a significant sex effect $(p<0.05)$ for body weight, body composition and relative organ weight, therefore sexes were analyzed separately. No difference in body weight was observed between diets in male (Figure 1B) or female (Figure 1C) offspring; however, we observed important differences in body composition, wherein male and female HF/S+M offspring had significantly lower fat mass compared to HF/S offspring, even though both groups consumed the same, nutritionally complete, AIN-93 diet for 13 weeks (Table 1). Male bone mineral content was significantly reduced in HF/S+M compared to HF/S (Table 1). No differences were observed in organ weight as a percentage of body weight for the heart, liver, kidney, cecum or colon in male and female adult offspring or testes in male offspring (Supplementary Table S1).

Energy intake was reduced in HF/S+M fathers compared to HF/S at 12 weeks of age (Figure 1D), which was similarly seen in female offspring at 9 weeks of age (Figure 1F). To examine hormonal influences on food intake, we assessed serum concentrations of glucagon-like peptide-1 (GLP-1) and peptide tyrosine tyrosine (PYY), both known to reduce food intake. GLP-1 was increased in adult HF/S+M male offspring compared to HF/S ( $p=0.03$ ) (Figure 1G). PYY was significantly increased in fathers consuming the HF/S+M diet $(p=0.02)$ (Figure $1 \mathrm{H})$. Higher PYY was similarly seen in adult female offspring $(p=0.01)$ (Figure $1 \mathrm{H})$.

Table 1. The body composition of fathers at mating at 12 weeks of age and offspring at 16 weeks of age.

\begin{tabular}{lccc}
\hline & HF/S & HF/S+M & $p$-Value \\
\hline Fathers & & & \\
\hline BMC $(\mathrm{g})$ & $15.82 \pm 0.45$ & $15.39 \pm 0.43$ & 0.85 \\
BMD $\left(\mathrm{g} / \mathrm{cm}^{2}\right)$ & $0.17 \pm 0.002$ & $0.17 \pm 0.002$ & 0.88 \\
Fat Mass $(\mathrm{g})$ & $143.82 .4 \pm 11.53$ & $123.0 \pm 11.81$ & 0.86 \\
Lean+ BMC $(\mathrm{g})$ & $507.76 \pm 13.84$ & $491.72 \pm 12.81$ & 0.92 \\
$\%$ Body Fat & $21.82 \pm 1.22$ & $19.63 \pm 1.37$ & 0.68 \\
\hline Male Offspring & & & 0.02 \\
\hline BMC $(\mathrm{g})$ & $17.07 \pm 0.18$ & $16.67 \pm 0.49$ & 0.34 \\
BMD $\left(\mathrm{g} / \mathrm{cm}^{2}\right)$ & $0.18 \pm 0.002$ & $0.17 \pm 0.002$ & 0.005 \\
Fat Mass $(\mathrm{g})$ & $135.11 \pm 5.95$ & $116.14 \pm 1.77$ & 0.56 \\
Lean+ BMC $(\mathrm{g})$ & $526.17 \pm 9.88$ & $546.88 \pm 14.48$ & \\
$\%$ Body Fat & $19.93 \pm 0.73$ & $16.83 \pm 0.84$ & 0.19 \\
\hline Female Offspring & & & 0.96 \\
\hline BMC $(\mathrm{g})$ & $11.78 \pm 0.53$ & $11.74 \pm 0.41$ & 0.005 \\
BMD $\left(\mathrm{g} / \mathrm{cm}^{2}\right)$ & $0.163 \pm 0.002$ & $0.164 \pm 0.003$ & 0.86 \\
Fat Mass $(\mathrm{g})$ & $100.84 \pm 18.78$ & $95.53 \pm 5.69$ & 0.10 \\
Lean+ BMC (g) & $304.36 \pm 9.29$ & $293.33 \pm 10.26$ & \\
$\%$ Body Fat & $23.54 \pm 3.40$ & $24.48 \pm 0.88$ & \\
\hline
\end{tabular}



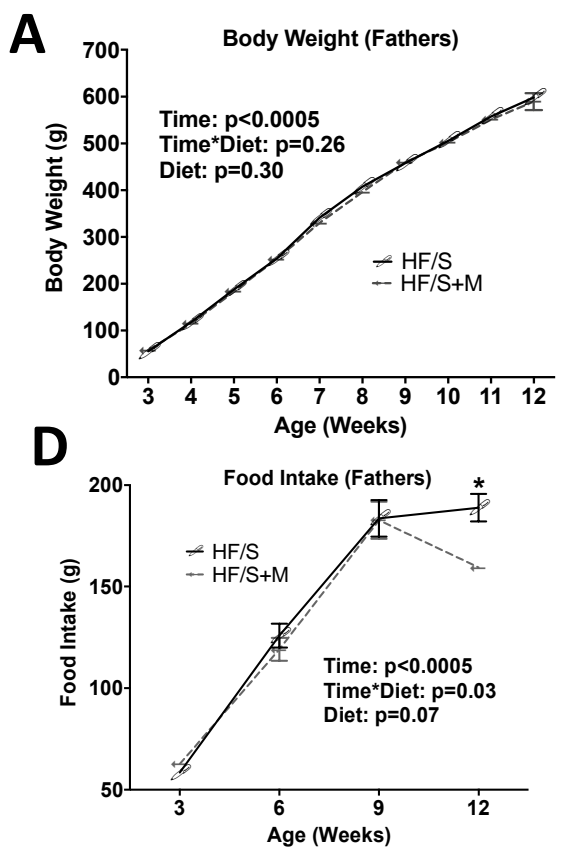
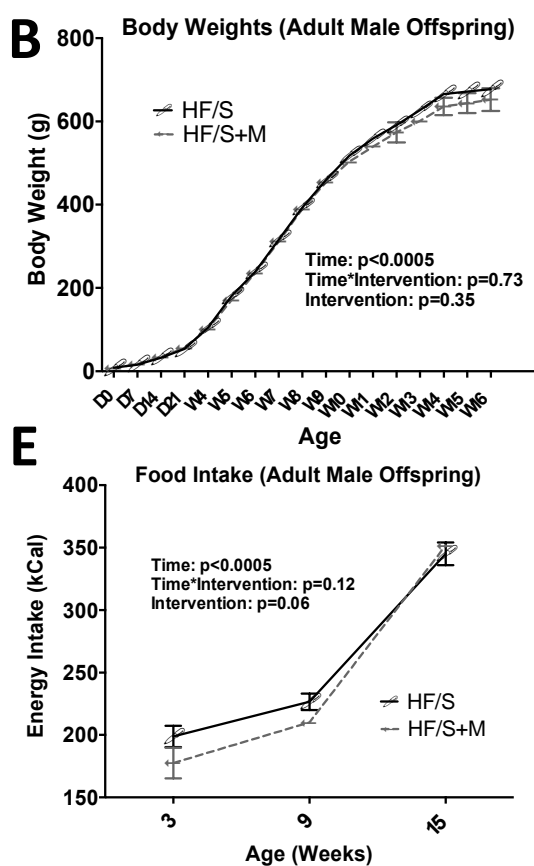

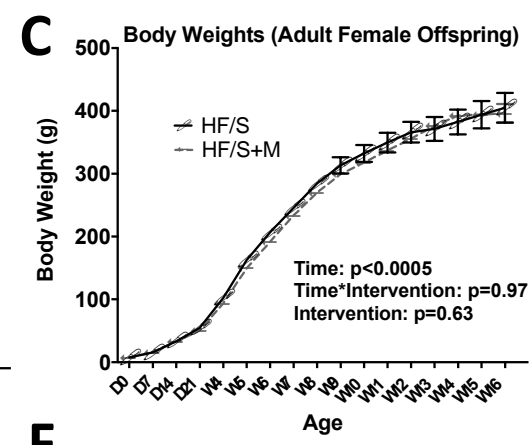

$\mathbf{F}$

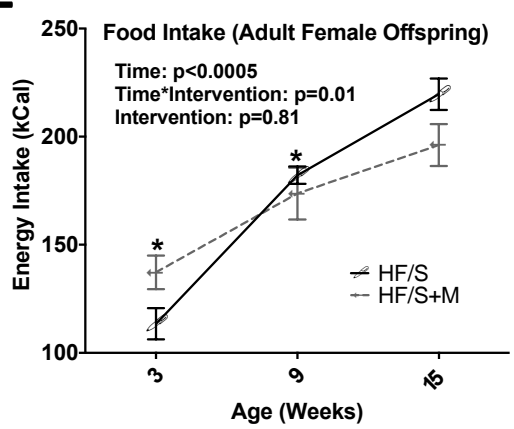

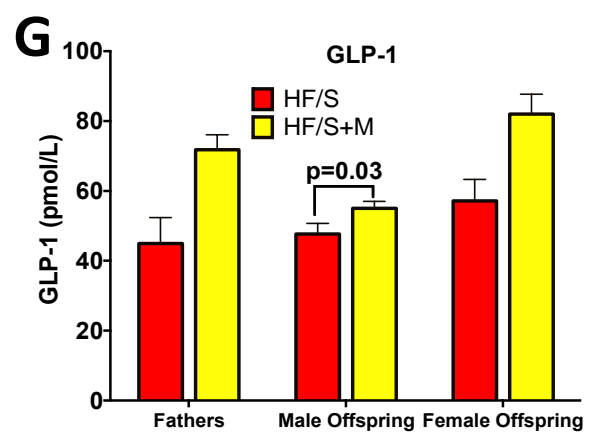

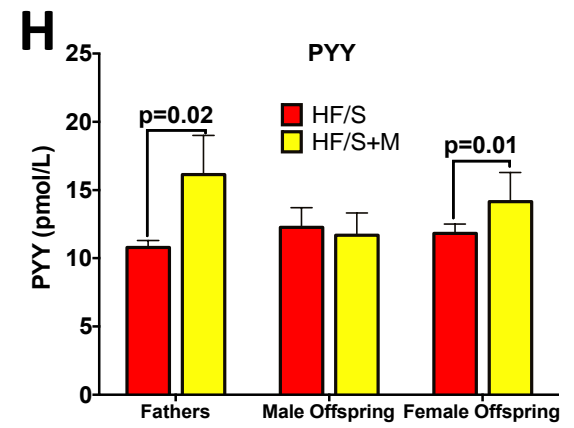

Figure 1. Body Weight, Food Intake and Gastrointestinal Peptides. The body weight of (A) fathers, (B) adult male offspring and (C) adult female offspring. The food intake of (D) fathers, (E) male offspring (F) female offspring; (G) serum glucagonlike peptide-1 (GLP-1) and (H) peptide tyrosine tyrosine (PYY). The values are means \pm SEM, $n=8-13$. In adult offspring, there was a significant sex effect in the overall model for bodyweight $(p=0.0001)$, food intake $(p=0.0001)$, GLP-1 ( $p=0.002)$; therefore, subsequent analysis was performed in males and females separately. ${ }^{*}$ represents a significant difference between groups, $p<0.05$.

Table 2. Reproductive markers for paternal fertility.

\begin{tabular}{lcc}
\hline & HF/S & HF/S+M \\
\hline Males (n) & 13 & 12 \\
Males cohabited with females & 13 & 12 \\
Nights cohabited until conception & $3.00 \pm 0.56$ & $2.00 \pm 0.33$ * \\
\# of successful pregnancies & 10 & 9 \\
Fertility Index (\%) & 77 & $13.3 \pm 0.9$ \\
\# of pups born alive (per father) & $14.7 \pm 0.6$ & 1 \\
\# of stillbirth pups & 3 & 99.9 \\
Pup survival (\%) & 97.8 & $49.2 \pm 1.0$ \\
Relative abundance of male pups (\%) & $51.2 \pm 4.1$ & $46.98 \pm 2.0$ \\
Relative abundance of female pups (\%) & $48.8 \pm 4.1$ &
\end{tabular}

\subsection{Paternal HF/S+M Reduces Fasting Insulin and Insulin Resistance}

Next, we examined the possible influence of paternal methyl donor diet supplementation on offspring metabolic parameters. Blood glucose concentrations during the oral 
glucose tolerance test (OGTT) and insulin tolerance test (ITT) in fathers (Figure 2A,D), male (Figure 2B,E) and female (Figure 2C,F) offspring were not independently affected by diet or the interaction of diet and time. Prior to said investigations, a potential sex effect was assessed for glycemia during the OGTT and ITT. Both tests yielded significant sex effects $(p<0.05)$, therefore sexes were analyzed separately. Although no differences were seen in glycemia, we did identify a significant decrease in serum insulin (Figure 2G) and insulin resistance as assessed by the Homeostatic Model Assessment of Insulin Resistance (HOMA-IR) (Figure 2H) in HF/S+M fathers compared to HF/S. This was not evident in offspring. We did not find any differences in hepatic triglyceride concentrations in fathers or offspring, although, we did observe a $40 \%$ reduction of hepatic triglyceride concentration in HF/S+M fathers $(41.0 \pm 1.7 \mu \mathrm{g}$ triglycerides $/ \mathrm{mg}$ of liver tissue) compared to HFS fathers $(68.7 \pm 3.5 \mu \mathrm{g} / \mathrm{mg})$ (Figure 2I).
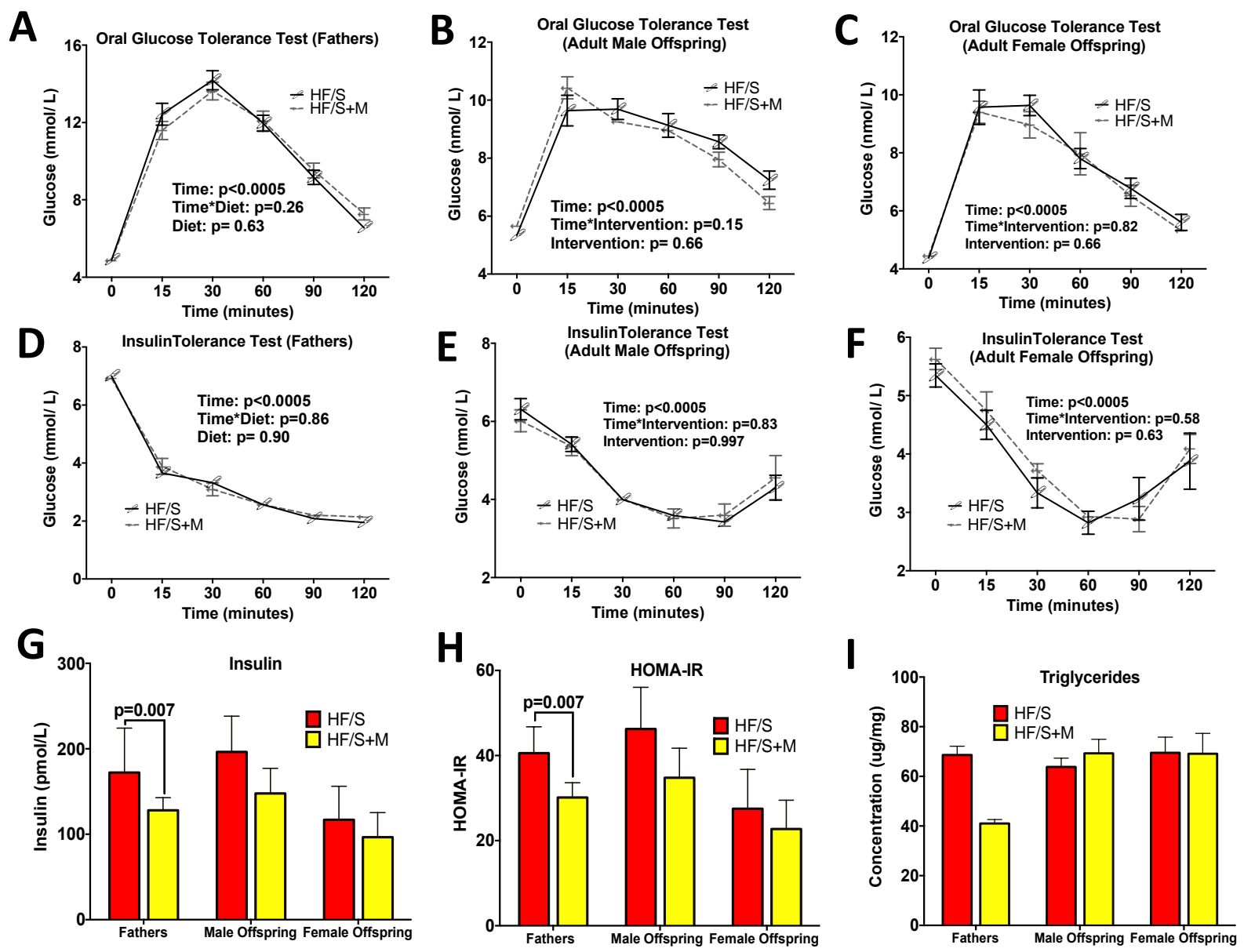

Figure 2. OGTT, ITT, Fasted Insulin, HOMA-IR and Hepatic Triglyceride Concentrations. The oral glucose tolerance test (OGTT) of (A) fathers, (B) adult male offspring and (C) adult female offspring. The insulin tolerance test (ITT) of (D) fathers, (E) male offspring, (F) female offspring. (G) Insulin levels, (H) Homeostatic Model Assessment of Insulin Resistance (HOMA-IR), (I) triglyceride content in hepatic tissue. The values are means $\pm \mathrm{SEM}, n=8-13$. In adult offspring, there was a significant sex effect in the overall model for OGTT ( $p=0.0001)$, ITT $(p=0.003)$, insulin $(p=0.0001)$, HOMA-IR ( $p=0.0001)$. Triglyceride sex effect was not significant. Since most assessments in adult offspring had a significant sex effect, subsequent analysis was performed in males and females separately.

\subsection{HF/S+M Improved Markers of Reproductive Performance in Fathers}

Since the effectiveness of maternal methyl supplementation on reproduction and pregnancy has been demonstrated [38], we examined whether similar effects may be 
observed following paternal methyl supplementation. We found no difference in the fertility index between groups, which was calculated as number of successful pregnancies divided by number of sperm positive fathers (Table 3). Notably, we found a significant difference in nights cohabited until conception, wherein $\mathrm{HF} / \mathrm{S}+\mathrm{M}$ resulted in fewer days to conception (Table 3). Similarly, we observed 300\% fewer stillbirths in the HF/S+M group compared to HF/S group (Table 3).

Table 3. MicroRNA expression in liver tissue.

\begin{tabular}{|c|c|c|c|}
\hline & $\mathrm{HF} / \mathrm{S}$ & $\mathrm{HF} / \mathrm{S}+\mathrm{M}$ & $p$-Value \\
\hline \multicolumn{4}{|l|}{ Fathers } \\
\hline miR-21 & $472.0 \pm 151.2$ & $701.5 \pm 244.9$ & 0.78 \\
\hline miR-24 & $0.05 \pm 0.01$ & $0.05 \pm 0.01$ & 0.67 \\
\hline miR-33 & $0.00017 \pm 0.00002$ & $0.0002 \pm 0.00006$ & 0.03 \\
\hline miR-34a & $1.02 \pm 0.17$ & $0.56 \pm 0.06$ & 0.002 \\
\hline miR-103 & $20.35 \pm 1.91$ & $21.65 \pm 3.94$ & 0.03 \\
\hline miR-107 & $0.32 \pm 0.01$ & $0.42 \pm 0.01$ & 0.04 \\
\hline $\operatorname{miR}-122 a$ & $5966.08 \pm 1122.78$ & $5822.70 \pm 1310.41$ & 0.51 \\
\hline miR-130a & $0.02 \pm 0.01$ & $0.01 \pm 0.01$ & 0.10 \\
\hline miR-143 & $0.04 \pm 0.01$ & $0.03 \pm 0.01$ & 0.70 \\
\hline miR-let-7c & $3.82 \pm 0.89$ & $5.05 \pm 0.95$ & 0.90 \\
\hline \multicolumn{4}{|c|}{ Male Offspring } \\
\hline miR-21 & $1591.20 \pm 722.13$ & $1539.55 \pm 476.72$ & 0.47 \\
\hline $\operatorname{miR}-24$ & $0.12 \pm 0.02$ & $0.15 \pm 0.04$ & 0.03 \\
\hline miR-33 & $0.00027 \pm 0.00004$ & $0.00034 \pm 0.0009$ & 0.006 \\
\hline miR-34a & $0.66 \pm 0.15$ & $0.57 \pm 0.10$ & 0.36 \\
\hline miR-103 & $17.78 \pm 2.70$ & $17.57 \pm 3.29$ & 0.44 \\
\hline miR-107 & $0.34 \pm 0.05$ & $0.33 \pm 0.03$ & 0.16 \\
\hline $\operatorname{miR}-122 a$ & $8370.09 \pm 1788.12$ & $18,602.11 \pm 5733.86$ & 0.001 \\
\hline miR-130a & $0.02 \pm 0.004$ & $0.01 \pm 0.003$ & 0.16 \\
\hline miR-143 & $0.03 \pm 0.01$ & $0.04 \pm 0.002$ & 0.009 \\
\hline miR-let-7c & $6.15 \pm 2.79$ & $7.00 \pm 3.02$ & 0.60 \\
\hline \multicolumn{4}{|c|}{ Female Offspring } \\
\hline miR-21 & $910.20 \pm 221.59$ & $723.52 \pm 468.95$ & 0.14 \\
\hline $\operatorname{miR}-24$ & $0.07 \pm 0.02$ & $0.07 \pm 0.01$ & 0.42 \\
\hline miR-33 & $0.0002 \pm 0.0001$ & $0.0001 \pm 0.00001$ & 0.0001 \\
\hline miR-34a & $1.07 \pm 0.35$ & $0.99 \pm 0.16$ & 0.09 \\
\hline miR-103 & $11.65 \pm 1.00$ & $15.47 \pm 2.16$ & 0.09 \\
\hline miR-107 & $0.57 \pm 0.11$ & $0.58 \pm 0.02$ & 0.11 \\
\hline miR-122a & $12,872.52 \pm 4519.43$ & $8144.62 \pm 1220.41$ & 0.21 \\
\hline miR-130a & $0.007 \pm 0.002$ & $0.01 \pm 0.003$ & 0.16 \\
\hline miR-143 & $0.02 \pm 0.006$ & $0.02 \pm 0.002$ & 0.16 \\
\hline miR-let-7c & $12.86 \pm 3.90$ & $6.2 \pm 0.64$ & 0.06 \\
\hline
\end{tabular}

\subsection{Paternal HF/S+M Consumption Improved Epigenetic Markers in Fathers and Offspring}

Due to the fact that DNA methylation is a key epigenetic regulator of adipose tissue development and gene regulation [17], we examined DNA methyltransferases 1, 3a and $3 \mathrm{~b}$, considered important catalysts of DNA methylation [39]. Using RT-PCR, we found reduced expression of DNMT3a in retroperitoneal adipose tissue in fathers in the HF/S+M group (Figure 3A). Adult offspring DNMTs were significantly affected by sex $(p<0.001)$, therefore male and female offspring were assessed separately. In adult female offspring, we saw significantly elevated retroperitoneal adipose tissue expression of DNMT1, DNMT3a and DNMT3b in the HF/S+M group (Figure 3C). 

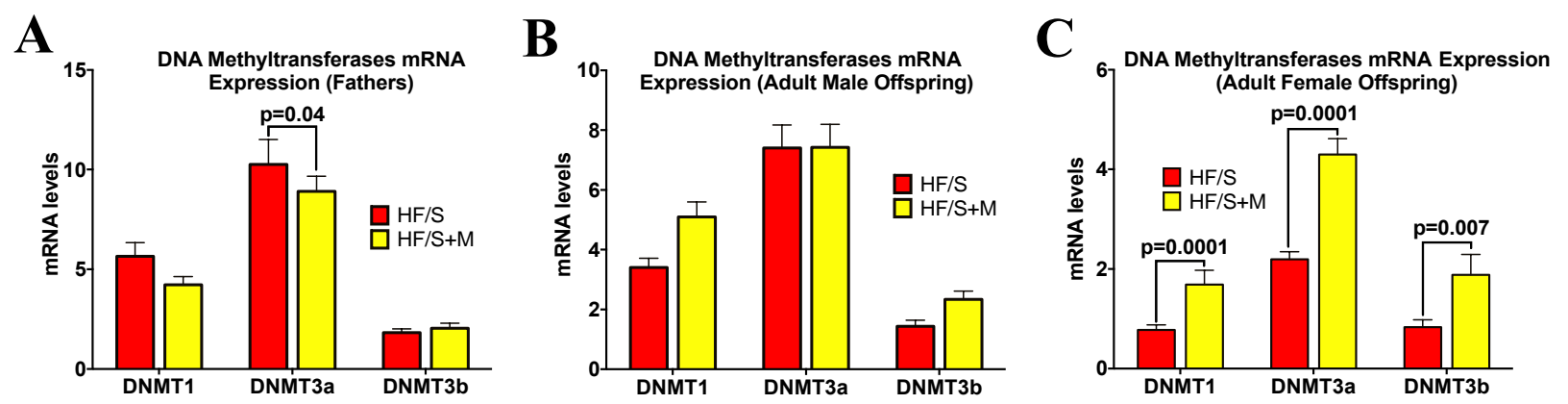

Figure 3. The adipose tissue mRNA levels of DNA Methyltransferases (DNMTs) in (A) fathers, (B) adult male offspring and (C) adult female offspring. The values are means \pm SEM, $n=8-13$. Sex differences were observed in DNMT1 ( $p=0.0001)$, DNM3a $(p=0.0001)$ and DNMT3b $(p=0.03)$; therefore, subsequent analysis was performed in males and females separately.

Given that the differential expression of several miRNAs in the liver has been associated with obesity and insulin resistance [40], we assessed a panel of 10 microRNAs in liver tissue. We identified 4 out of 10 microRNAs that were differentially expressed in HF/S+M fathers; 3 were upregulated (miR-33, miR-103 and miR-107) and 1 was downregulated (miR-34a) (Table 3). In adult males, 4 microRNAs were differentially expressed; miR-24, miR-33, miR-122a, miR-143 were all upregulated in HF/S+M offspring (Table 3). In females, miR-33 was downregulated in HF/S+M versus HF/S offspring (Table 3).

\subsection{Gut Microbiota and Short Chain Fatty Acids Are Impacted by Paternal HF/S+M Consumption Intergenerationally}

Paternal methyl donor supplementation with HF/S diet impacted offspring fecal microbiota as seen by $16 \mathrm{~S}$ rRNA sequencing of the V3 and V4 regions. There were no differences in alpha diversity at weaning in fathers or offspring (Supplementary Table S2), however, at 9 weeks of age, fathers supplemented with methyl donors showed significantly higher alpha diversity compared to the HF/S group as seen by Chao1 $(p=0.049)$ (Table 4$)$. Interestingly, the opposite was observed in female adult offspring at 9 weeks of age, where $\mathrm{HF} / \mathrm{S}+\mathrm{M}$ group displayed reduced alpha diversity compared to HF/S group across all three alpha diversity indices $(p<0.01)$ (Table 4$)$. None of these differences persisted to 12 or 15 weeks of age in fathers or offspring (Supplementary Table S3). Only a trend towards a difference in beta diversity in fathers at 12 weeks of age was observed $(p=0.055)$ (Figure 4A) while no differences were found in offspring at any age (Figure $4 B, C)$. Linear discriminant analysis effect size (LEfSe) showed that fathers fed a HF/S+M diet had increased relative abundance of Actinobacteria, Adlercreutzia, Coriobacteriales, and Eggerthellaceae at 12 weeks of age compared to HF/S (Figure 4D). Adult HF/S male offspring at 15 weeks of age, showed an increased abundance of Clostridiales compared to HF/S+M (Figure 4E). $\mathrm{HF} / \mathrm{S}+\mathrm{M}$ males showed an increased abundance of Defluviitalaceae compared to HF/S (Figure 4E). Adult HF/S+M females exhibited an increased abundance of Butyrivibrio (Figure 4F).

The Venn diagrams show that paternal HF/S (Figure 4G) and HF/S+M (Figure 4H) groups have a total of 1422 and 1207 amplicon sequence variants (ASVs), respectively, at 12 and 15 weeks of age in fathers and offspring. Of those ASVs, the offspring shared $45 \%$ with the fathers in the HF/S group and $41 \%$ among HF/S+M.

Paternal HF/S intake supplemented with methyl donors altered cecal short chain fatty acid (SCFA) concentrations in fathers and offspring. Paternal HF/S+M significantly increased cecal butyrate (Figure 4I), which persisted in adult male offspring (Figure 4J). Adult female offspring showed significantly reduced isobutyrate and elevated isovalerate in the HF/S+M group compared to the HF/S group (Figure $4 \mathrm{~K}$ ). 

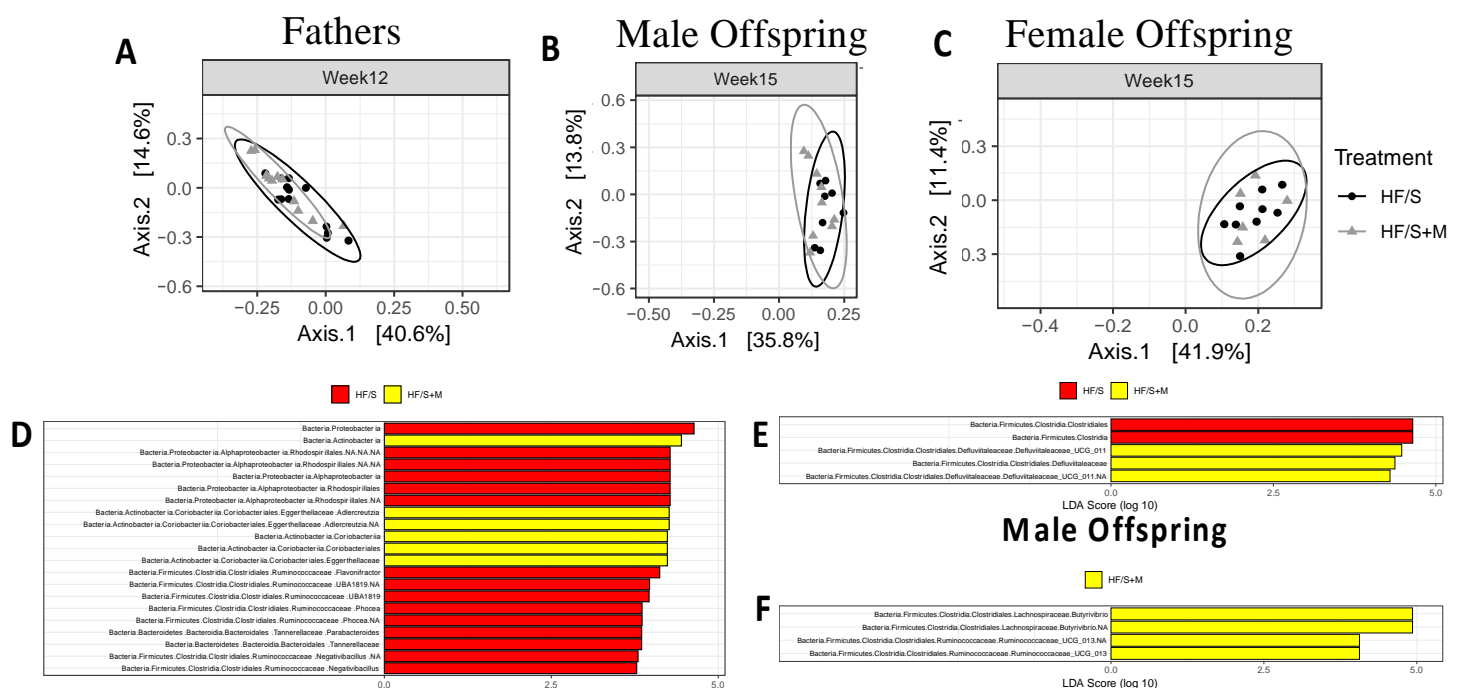

Fathers

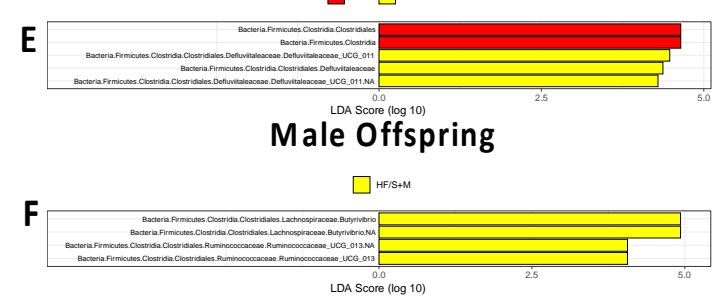

Female Offspring

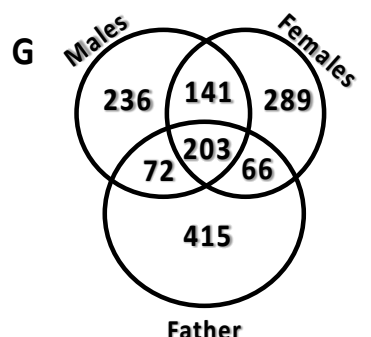

[High Fat/ Sucrose]

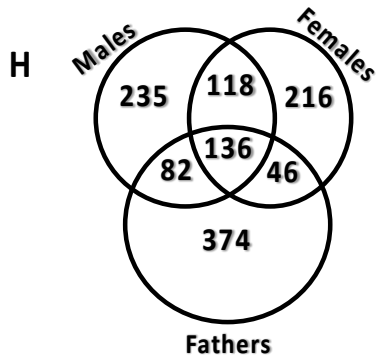

[High Fat/ Sucrose+ Methyl Donors]
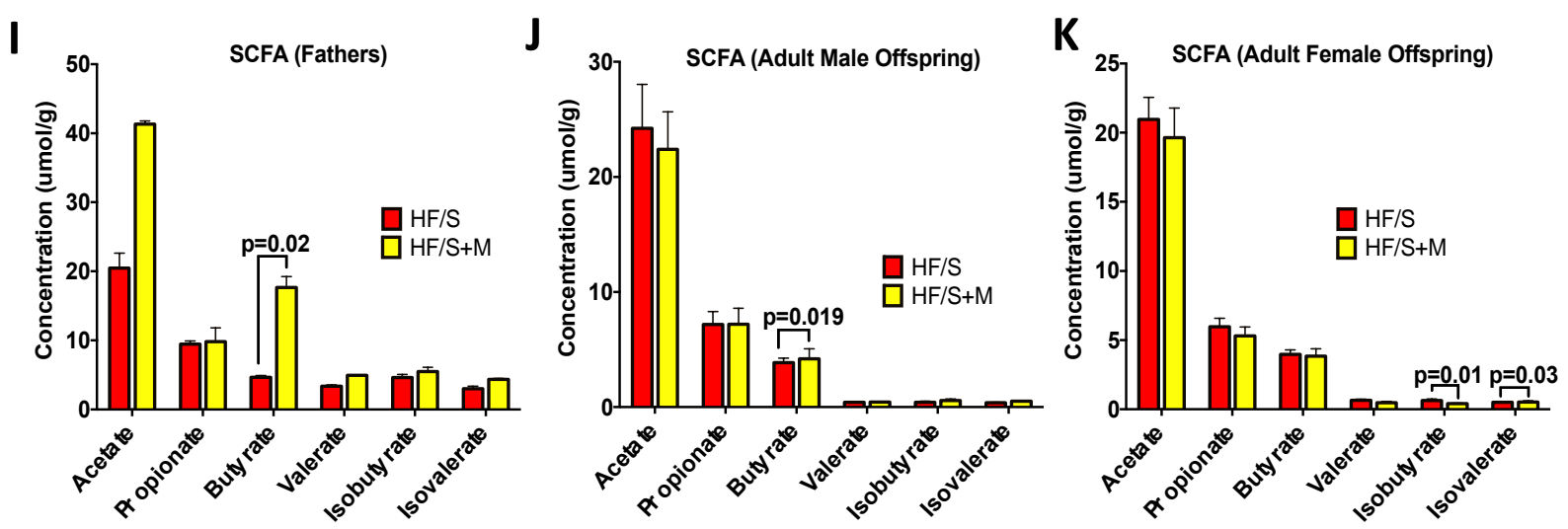

Figure 4. Fecal microbiota comparisons of fathers fed HF/S and HF/S+M and the intergenerational similarities in male and female offspring. Beta Diversity of (A) paternal at 12 weeks of age, (B) male offspring and (C) female offspring at 15 weeks of age, assessed with principal coordinates analysis (PCoA) using a Bray-Curtis distance matrix. Linear discriminant analysis effect size (LefSe) comparison of (D) Fathers at 12 weeks of age, (E) Male offspring and (F) Female offspring at 15 weeks of age. A Venn diagram comparison of ASVs that overlap between fathers and offspring and those only present in offspring, stratified by sex and (G) HF/S diet (H) HF/S+M diet. Cecal Short Chain Fatty Acids in: (I) paternal, (J) adult male offspring and $(\mathbf{K})$ adult female offspring at euthanasia. Values are means \pm SEM, $n=8-13(p<0.05)$. 
Table 4. Alpha diversity for fathers and offspring at 9 weeks of age.

\begin{tabular}{cccc}
\hline & HF/S & HF/S+M & $p$-Value \\
\hline Paternal & & & \\
\hline Chao1 & $209.19 \pm 8.37$ & $265.78 \pm 26.87$ & 0.049 \\
Shannon & $3.87 \pm 0.09$ & $3.95 \pm 0.13$ & 0.61 \\
Simpson & $0.95 \pm 0.004$ & $0.95 \pm 0.01$ & 0.99 \\
\hline Male Offspring & & & 0.63 \\
Chao1 & $182.82 \pm 28.3$ & $168.67 \pm 7.09$ & 0.54 \\
Shannon & $3.76 \pm 0.08$ & $3.83 \pm 0.08$ & 0.55 \\
Simpson & $0.95 \pm 0.01$ & $0.95 \pm 0.01$ & \\
\hline Female Offspring & & & 0.004 \\
\hline Chao1 & $192.31 \pm 11.22$ & $139.44 \pm 11.48$ & 0.002 \\
Shannon & $3.99 \pm 0.06$ & $3.67 \pm 0.07$ & 0.004 \\
Simpson & $0.96 \pm 0.003$ & $0.95 \pm 0.004$ & \\
\hline
\end{tabular}

The values are means \pm SEM, $n=8-13$.

\section{Discussion}

We present evidence that supplementing a paternal HF/S diet with a methyl-donor cocktail of betaine, choline, folic acid and vitamin B12 before conception reduced energy intake, fasting serum insulin and insulin resistance alongside alterations in gut microbial signatures, epigenetic markers modulating metabolism, and reproductive outcomes in fathers. Paternal HF/S+M also appears to reduce fat mass and alter microRNA and gut microbial signatures in adult male and female offspring compared to HF/S intake alone (see Figure 5 for a summative schematic).

It has been postulated that epigenetic changes owing to malnutrition in utero have a substantial impact on transgenerational metabolic abnormalities [41]. Etiological studies have demonstrated that paternal BMI affected offspring BMI in a way that was independent of, but additive to, the BMI of the mother [42,43]. These findings in humans were furthered through a seminal study by Masuyama and colleagues in 2016 [44]. They examined whether high-fat diet-induced-obesity in fathers before conception would impact the metabolic status of offspring, as seen by the epigenetic status of the adiponectin and leptin gene promotors in a mouse model [44]. They also investigated whether a normal, control diet would reverse the epigenetic changes in subsequent generations [44]. In the F1 generation, epigenetic changes were diminished, whereas in the F2 generation, epigenetic changes caused by a paternal high fat diet were completely absent in male offspring [44]. Based on the reversal seen with a control diet, we sought to examine whether a HF/S diet supplemented with methyl donors could attenuate some of the detrimental metabolic outcomes caused by a pre-conception paternal HF/S diet in the F1 progeny. Our model uniquely shows that a paternal high fat diet supplemented with methyl-donors attenuates the accumulation of fat mass in adult male and female offspring. This was accompanied by changes in the expression of DNMTs and miRNAs, albeit differently according to sex. 


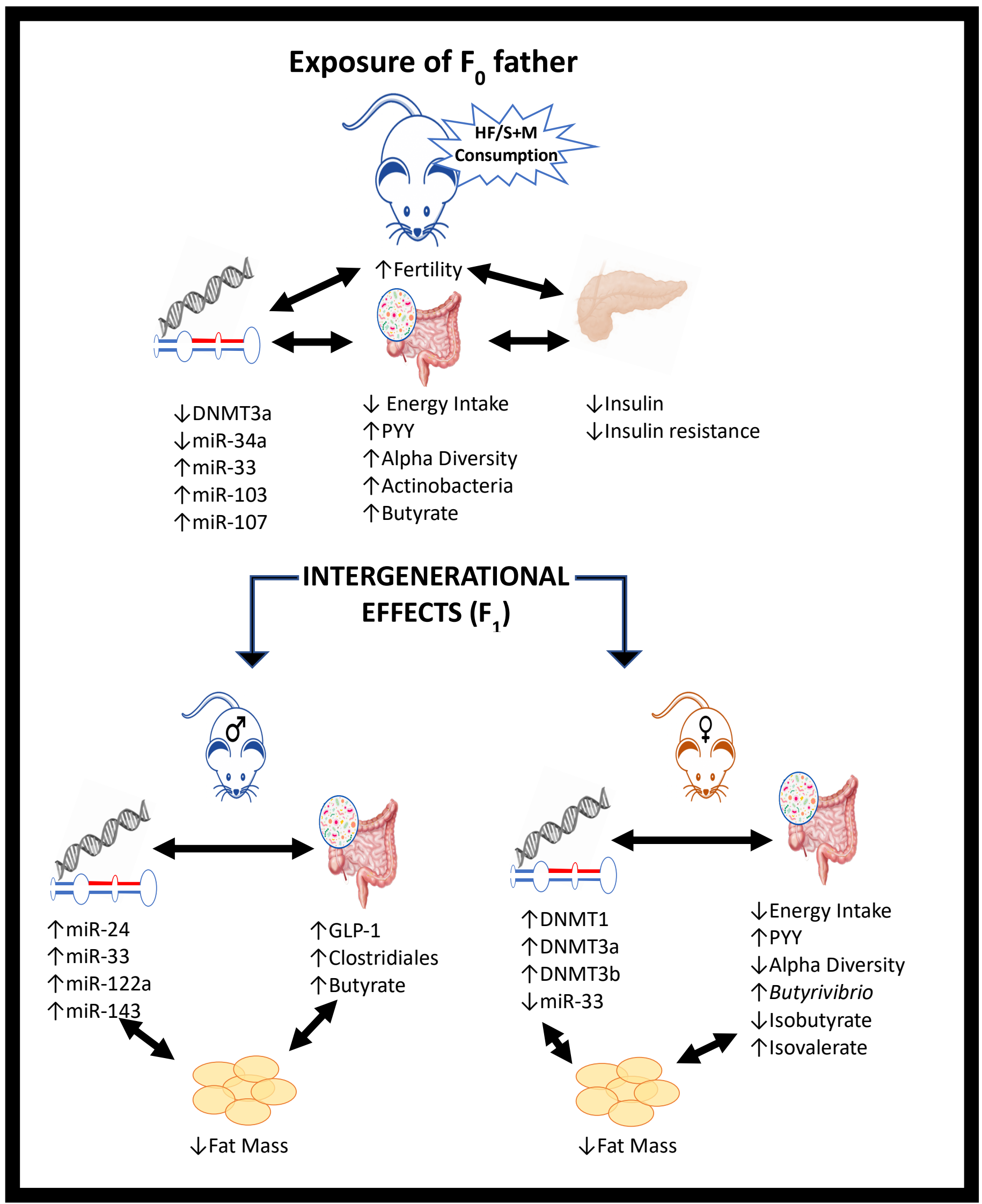

Figure 5. An overall summary of the major findings in fathers and adult offspring following a HFS diet, supplemented with a methyl donor cocktail of betaine, choline, folic acid and vitamin B12. All data are compared to a control HF/S diet. 
Previous work has demonstrated that epigenetic changes, including DNA methylation play an important role in modulating gene expression $[45,46]$ and have key roles in obesity-associated gene expression by governing transcriptional dysregulation [47,48] One such transcriptional dysregulation occurs in the expression of genes involved in fat metabolism causing the decreased expression of adiponectin in adipose tissue of high-fat diet-induced obese models (DIOs) [49]. Given that the gut microbiota participates in epigenetic processes through its metabolites, such as folate and SCFAs, Yao et al. [49] investigated whether altering the gut microbiota with antibiotics affected the transcriptional expression of obesity-related genes such as adiponectin through epigenetic regulation. They showed that antibiotics given to DIO animals upregulated the expression of adiponectin in adipose tissue which was accompanied by a reduction in DNA methylation of the adiponectin promoter and the downregulation of DNMT1 and 3a [49]. Previous work from the same lab found that SCFA supplementation in a DIO model reversed the transcriptional alterations in adiponectin in adipose tissue, which was again mediated by reduced expression of DNMTs including DNMT3a [50]. This is consistent with our findings, wherein methyldonor supplemented HF/S fathers showed reduced expression of DNMT3a in adipose tissue. Although, this was not accompanied by reductions in adiposity directly in the HFS+M fathers, we did see reductions in HFS+M offspring fat mass, suggesting a potential heritable influence of reduced DNMT3a expression in fathers and a subsequent reduction in adiposity in offspring. Although both male and female HFS+M offspring had reduced fat mass, it is interesting that female HF/S+M offspring showed increased expression of DNMTs including: 1, 3a and $3 \mathrm{~b}$, suggesting a sex-specific effect of one carbon metabolism. This might be explained by sex-specific disparities in epigenetic machinery like DNA methylation and histones that have been reported previously [51,52]. Alternatively, the sex difference observed may be due to the established difference in fat distribution and homeostasis between males and females [53], which may also alter the epigenetic machinery and function in adipose tissue, including DNA methylation.

The gut microbiota produces SCFAs which interact with the host epigenetic machinery, including DNA and histones, which are able to influence the host's epigenetic state and function $[54,55]$ including lipid metabolism and ultimately weight regulation. The gut microbiota synthesize choline, thiamin (vitamin B1), vitamin B2, nicotinic acid (vitamin B3), pantothenic acid (vitamin B5), pyridoxine (vitamin B6), biotin (vitamin B7), folate, and vitamin B12 [56,57]. Whether or not dietary supplementation with these methyl donors has the ability to correct some of the microbial dysbiosis observed with HF/S consumption is not well understood, particularly with regards to intergenerational effects. In HFS+M fathers, we saw increased relative abundance of Adlercreutzia, Coriobacteriales, and Eggerthellaceae. Coriobacteriales exert saccharolytic activity (fermentation of carbohydrates) in the gut [58], which could reflect the higher butyrate concentrations we detected in the cecal matter of HFS+M fathers and male offspring. Further, there has been a suggestion that members of the order Coriobacteriales may be indicators of a healthy gut microbiota community [59]. It is of interest that supplementing a HF/S diet with polyphenol-rich cranberry powder increased the relative abundance of both Coriobacteriales and Eggerthellaceae in mice [60]. Eggerthellaceae, which has been linked to positive effects in lipid metabolism, was also inversely correlated with body weight gain in mice [60]. Although relatively little is known about the genera Adlercreutzia, it has been shown in pubertal human subjects to be positively associated with testosterone [61]. Adlercreutzia have also been shown to metabolize phytoestrogens [62] and it is therefore possible that this bacteria could be affected by sex hormones, although this warrants further investigation.

Offspring gut microbiota did not differ as demonstrated by a principal coordinates analysis (PCoA) beta diversity assessment and little difference was observed at lower taxonomic levels as seen by LEfSe analysis. This might be indicative of the diminished metabolic influence of a paternal HF/S diet in the F1 progeny, as discussed in previous work [44]. Interestingly, however, males showed increased abundance of Defluviitaleaceae, which is reported to increase the statin efficacy of Rosuvastatin, a blood lipid-lowering 
agent in hyperlipidemia in humans [63]. Therefore, although very little is currently known about these bacteria, it is possible that the increased Defluviitaleaceae in male offspring could have contributed to altered lipid metabolism and reduced body fat mass.

MicroRNAs (miRNAs) are important post-transcriptional regulators of gene expression that have been implicated in pathways underpinning metabolic disease in multiple organs including the pancreas, liver, adipose tissue, and skeletal muscle [64]. Here, HFS+M fathers exhibited decreased hepatic expression of miR-34a and increased miR-103, miR-107 and miR-33. HFS+M female offspring similarly showed a trend towards decreased miR-34a in liver tissue $(p=0.09)$. MiR-34a is an important mediator in lipid homeostasis in the liver [65]. MiR-34 is characteristically elevated in the liver of DIO mice [66]. For instance, mice treated with anti-sense oligonucleotides that target miR-34a experienced improvements in glucose tolerance and insulin resistance, suggesting miR-34 to be a crucial target to mitigate insulin resistance. We showed that oral supplementation of a methyl-donor cocktail in our DIO rat model elicited similar results, wherein our HF/S+M fathers displayed improvements in insulin resistance. Additionally, Tryndyak and colleagues [67] showed that circulating miR-34a is the strongest correlate with non-alcoholic fatty liver diseasespecific liver pathomorphology, wherein increased levels of plasma miR-34a increase overall liver pathology, as measured by total hepatic lesions and severity [67]. Although not reaching significance, we did observe a $40 \%$ decrease of triglyceride concentrations in the livers of HF/S+M fathers compared to HF/S.

MiR-103 and 107 have been previously identified as negative regulators of insulin sensitivity [68], and increased hepatic expression has been observed in both humans and murine models of metabolic disease and/or high fat diet consumption [68]. However, there are also studies suggesting that increasing miR-103 and miR-107 expression is beneficial. For example, obesity induced by a high-fat, high-cholesterol diet in mice decreased the expression of hepatic miR-103 and -107, while simultaneously increasing fatty acid synthase protein (FASN), a modulator of fatty acid synthesis [69]. FASN is a putative miR-107 target. Furthermore, Zhang et al. [70] showed that overexpression of miR-103 in mice fed a diet high in fructose and sucrose alleviated hepatic lipid accumulation and suppressed lipogenesis in the liver. We postulate that the increased expression of HF/S+M paternal hepatic miR-107 in our study could have reduced FASN, contributing to the observed reduction in fat mass in male and female adult offspring.

MiR-33 is yet another important regulator of lipid metabolism [71]. Inhibiting miR-33 function in vivo increases circulating high-density lipoprotein concentrations and lowers very-low-density lipoprotein and triglycerides by increasing the expression of fundamental enzymes involved in fatty acid oxidation [72]. Adult female offspring of HF/S+M fathers exhibited reduced expression of miR-33, potentially explaining the concurrent reduction in adiposity in females. Additionally, miR-33 plays an important role in regulating insulin signaling by targeting insulin receptor substrate 2 , a vital component of insulin signaling in the liver [73]. Conversely, miR-33-knockout in mice showed deleterious outcomes, including increased obesity, insulin resistance and food intake [74]. This study elicited a miR-33 conundrum, which was similarly observed in our study. Methyl donor supplementation increased hepatic miR-33 expression in fathers and adult male offspring but reduced it in females. In HFS+M fathers, reduced miR-33 expression occurred alongside reduced insulin resistance, while in HFS+M offspring the disparate expression was associated with reduced adiposity in both male and female HFS+M offspring. We also observed reduced energy intake in HFS+M fathers at 12 weeks of age and 9 weeks of age in female offspring, which could be attributed in part to increased levels of appetite regulating gut hormones like PYY. It is worth noting, with the exception of miR-33 in fathers and adult male offspring, we observed differentially acquired microRNAs intergenerationally. This may be due to the fact that the epididymis, containing mature sperm, facilitates altered microRNA transfer enacted by epididymosomes [75]. Future research should assess this epididymis-specific microRNA alteration in vivo. 
In male HFS+M offspring, we saw a substantial increase in miR-122a. Benatti et al. [76] showed that maternal high-fat diet consumption modulates hepatic lipid metabolism and microRNA expression in offspring, most notably showing reductions in miR-122a in DIO mice. They concluded that a maternal high fat diet impairs offspring lipid metabolism and miRNA expression, which may have lasting metabolic impairments in adulthood [76]. We found that paternal HF/S supplemented with methyl donors ameliorated these effects and in turn increased miR-122a in male offspring.

To our knowledge, no human studies have been conducted that examine whether paternal methyl-donor supplementation could mitigate some of the detrimental reproductive and metabolic effects of a paternal HF/S diet. Given the increasing recognition of the importance of paternal health and nutritional intake on programming metabolism in offspring, future work is warranted to determine the potential for individual methyl donors or cocktails such as we have used here to positively affect male fertility and pregnancy outcomes in humans.

\section{Materials and Methods}

\subsection{Animal Model and Dietary Treatment}

Maintained in a temperature and humidity-controlled facility, twenty-four male Sprague Dawley rats (Charles River Laboratories, Montreal, QC, Canada) were randomized to one of two dietary interventions: (1) high fat/high sucrose (HF/S) or (2) high fat/high sucrose supplemented with a methyl donor cocktail (HF/S+M) [betaine ( $5 \mathrm{~g} / \mathrm{kg}$ diet), choline (5.37 g/ kg diet), folic acid (5.5 mg/ kg diet), vitamin B12 (0.5 mg g/ kg diet); (Sigma Aldrich, Oakville, ON, Canada) according to previous work [77-79]. HF/S diets were purchased from Dyets Inc. (Bethlehem, PA, USA) (DYETS\# 103915: age 3-9 weeks; DYETS\# 102412: weeks 10-12). Diet composition is provided in Supplementary Table S4. At 12 weeks of age, a virgin female Sprague Dawley rat was co-housed with a male rat from one of the dietary interventions during the dark cycle for as many consecutive nights until a copulation plug was identified. During the light cycle, females were given an American Institute of Nutrition (AIN)-93G diet and males were returned to their designated dietary intervention with water ad libitum. During pregnancy and lactation, dams consumed an AIN-93G diet. In an effort to limit differences in energy intake due to variances in litter size, one day after birth, litters were culled to 10 offspring ( $n=5$ males; $n=5$ females). Litters that were less than $n=10$ were increased via cross-fostering with offspring from another litter belonging to the same treatment group. At 3 weeks of age, one male and one female from each litter (considered as $n=1$ ) were weaned onto AIN-93G diet (weeks 3-9) and AIN-93M (weeks 10-12) and water ad libitum for 13 weeks. This study was approved by the University of Calgary Animal Care Committee (AC18-0074) and conformed to the Guide to the Care and Use of Laboratory Animals.

\subsection{Body Weight, Food Intake and Body Composition}

Throughout the duration of the study, paternal and offspring bodyweights were quantified weekly; food intake was quantified every 3 weeks. A Dual X-ray Absorptiometry (DXA) scan (Hologic ODR 4500; Hologic Inc., Marlborough, MA, USA) was used to assess body composition 1 day prior to sacrifice. To ensure animals remained still during the scan, animals were lightly anaesthetized using isoflurane. Using QDR software for small animals, bone mineral content/density (BMC/BMD) $\left(\mathrm{g}\right.$ and $\left.\mathrm{g} / \mathrm{cm}^{2}\right)$, fat mass $(\mathrm{g})$, lean mass (g) and body fat \% were quantified.

\subsection{Oral Glucose Tolerance Test (OGTT) and Insulin Tolerance Test (ITT)}

At 10 and 14 weeks of age, in fathers and offspring, respectively, rats underwent a $12 \mathrm{~h}$ fast and a blood glucose measurement was obtained via tail nick and a One Touch Ultra ${ }^{\circledR}$ 2 glucose meter (Lifespan, Burnaby, BC, Canada), accounting for the 0 min timepoint. Additional blood glucose measurements were collected at 15, 30, 60, 90 and 120 min after a $2 \mathrm{~g} / \mathrm{kg}$ glucose solution was administered via oral gavage. 
In fathers and offspring at 11 and 15 weeks of age respectively, rats were fasted for $6 \mathrm{~h}$ and blood glucose measured via tail nick using a One Touch Ultra ${ }^{\circledR} 2$ glucose meter (Lifespan, Burnaby, Canada) accounting for the 0 min timepoint. Additional blood glucose measurements were collected at 15, 30, 60, 90 and 120 min after an intraperitoneal injection of insulin $(0.75 \mathrm{U} / \mathrm{kg})$.

\subsection{Tissue Harvest and Blood Insulin, GLP-1, PYY and HOMA-IR}

The animals were anesthetized using isoflurane and denied access to food overnight for a $12 \mathrm{~h}$ fast; $1 \mathrm{~mL}$ of blood was collected from the portal vein in a chilled tube containing diprotinin-A $(0.034 \mathrm{mg} / \mathrm{mL}$ blood; MP Biomedicals, Irvine, CA, USA), Sigma protease inhibitor ( $1 \mathrm{mg} / \mathrm{mL}$ blood; Sigma Aldrich, Oakville, ON, Canada) and Roche Pefabloc ( $1 \mathrm{mg} / \mathrm{mL}$ of blood; Roche, Mississauga, ON, Canada). Plasma was collected after centrifugation and stored in $-80^{\circ} \mathrm{C}$ until insulin, peptide tyrosine tyrosine (PYY) and glucagon-like peptide 1 (GLP-1) were measured using a Rat Metabolic Multiplex Array (MRDMET) (Millipore, St. Charles, MO, USA) (Eve Technologies, Calgary, AB, Canada). The animals were henceforth euthanized via decapitation and heart, liver, kidney, cecum, colon and male testes were weighed and stored in $-80^{\circ} \mathrm{C}$ until analysis. The Homeostatic Model Assessment of Insulin Resistance (HOMA-IR) was used to estimate insulin resistance using the following formula [80]:

$$
\text { HOMA-IR }=[\text { glucose }(\mathrm{mmol} / \mathrm{L}) \times \text { insulin }(\mathrm{mIU} / \mathrm{mL})] / 22.5
$$

\subsection{Hepatic Triglyceride Analysis}

Triglyceride concentrations were assessed from a starting amount of $25 \mathrm{mg}$ of liver derived from the right lobe, using the GPO reagent set according to manufacturer's instructions (Pointe Scientific Inc., Lincoln Park, MI, USA).

\subsection{Gut Microbiota $16 S$ rRNA Gene Sequencing}

Baseline fecal matter was collected at 3 weeks of age in fathers and offspring. Additional fecal matter was collected at 9 and 12 weeks of age in fathers and 9 and 15 weeks of age in offspring. All fecal matter was snap frozen and stored at $-80^{\circ} \mathrm{C}$ until analysis. Gut microbial $16 \mathrm{~S}$ rRNA gene sequencing was performed according to our previous work [81,82]. Briefly, a FastDNA spin kit for feces (MP Biomedicals, Lachine, QC, Canada) was used to extract bacterial DNA according to manufacturer's guidelines. Bacterial DNA concentrations were diluted to $4 \mathrm{ng} / \mathrm{uL}$. The MiSeq Illumina platform was utilized to amplify the V3 and V4 region of the 16S rRNA gene (Illumina, San Diego, CA, USA) at the Centre for Health Genomics and Informatics (University of Calgary, Calgary, AB, Canada).

\subsection{Cecal Short Chain Fatty Acids}

SCFAs were extracted from cecal matter and assessed using reverse-phase HPLC on a c18 column as previously described [83].

\subsection{RT-PCR of DNA Methyltransferase mRNA and microRNAs}

Total RNA was extracted from retroperitoneal adipose tissue using the RNAeasy Lipid Tissue Mini Kit (Qiagen) and then reverse-transcribed into cDNA using the SuperScript II RT (Qiagen). RT-PCR was performed as previously described [84]. The mRNA expression of DNA methyltransferase (DNMT) 1, $3 \mathrm{a}$ and $3 \mathrm{~b}$ of all samples were analyzed relative to the $18 \mathrm{~S}$ housekeeping control gene using the $2^{-\Delta \mathrm{CT}}$ method [85]. The amplicon context sequences are provided in Supplementary Table S5.

Using the miRNeasy mini kit (Qiagen), following the manufacturer's instructions for Purification of Total RNA, including Small RNA from animal tissue, microRNAs were isolated from liver tissue and then reverse transcribed into cDNA using the miScript II RT kit (Qiagen). RT-PCR was conducted as previously described [84], wherein all microRNAs 
were analyzed relative to SNORD68 and SNORD96A controls genes using the $2^{-\Delta C T}$ method [85]. MicroRNA primer sequences are listed in Supplementary Table S6.

\subsection{Statistical and Bioinformatics Analysis}

Statistical comparisons for all outcomes, except $16 \mathrm{~S}$ rRNA sequencing data, were performed using IBM ${ }^{\circledR}$ SPSS Statistics, version 24.0. A multivariate general linear model (GLM) was used to determine a sex effect between male and female offspring. If a sex effect was identified, males and females were analyzed separately using an independent samples t-test. Outcomes with multiple time points were analyzed using a repeated measures GLM, wherein diet was the between-subject factor and time was the within-subject factor. Identification of a significant interaction between diet and time was followed with an independent samples $t$-test to determine differences between dietary groups. All data were presented as mean \pm standard error of the mean (SEM).

Sequence data were first quality filtered using the filterAndTrim, assignTaxonomy and assignSpecies functions with the $R$ package dada2 (version 1.10.1) [86]. Diversity analysis was conducted using $R$ package phyloseq (version 1.24.2) [87], where alpha diversity was determined using ANOVA and Tukey HSD if significant. Beta diversity was assessed using PCoA (principal coordinates analysis) on a matrix of Bray-Curtis distances. A permutational multivariate analysis of variance (PERMANOVA) was performed to determine significant differences between dietary interventions. Differentially abundant features were assessed using a LEfSe analysis [88], using a significance of alpha $=0.05$ and default parameters. Significance for all outcomes was set at $p \leq 0.05$, unless stated otherwise.

Supplementary Materials: Supplementary Materials can be found at https://www.mdpi.com/1422 $-0067 / 22 / 2 / 689 / \mathrm{s} 1$.

Author Contributions: Conceptualization, F.C. and R.A.R.; Data curation, J.M.D.; Formal analysis, F.C. and A.S.; Funding acquisition, R.A.R.; Investigation, F.C.; Project administration, F.C. and R.A.R.; Supervision, R.A.R.; Writing—original draft, F.C.; Writing—review \& editing, F.C., A.S., J.M.D. and R.A.R. All authors have read and agreed to the published version of the manuscript.

Funding: This research was funded by Natural Science and Engineering Research Council, NSERC RGPIN/03773-2016.

Institutional Review Board Statement: This study was conducted according the Guide to the Care and Use of Laboratory Animals and approved by the University of Calgary Animal Care Committee (AC18-0074 May 11, 2017).

Informed Consent Statement: Not applicable.

Data Availability Statement: Data is available from the corresponding author upon reasonable request.

Acknowledgments: The authors would like to thank Kristine Lee, Faculty of Kinesiology, and Dawn Martin, University of Calgary, for their technical assistance; and Shelly Wegener and the Richard Pon, Centre for Health Genomic and Informatics facility at the University of Calgary for their technical assistance and support with the $16 \mathrm{~S}$ rRNA sequencing and analysis.

Conflicts of Interest: The authors declare no conflict of interest. 


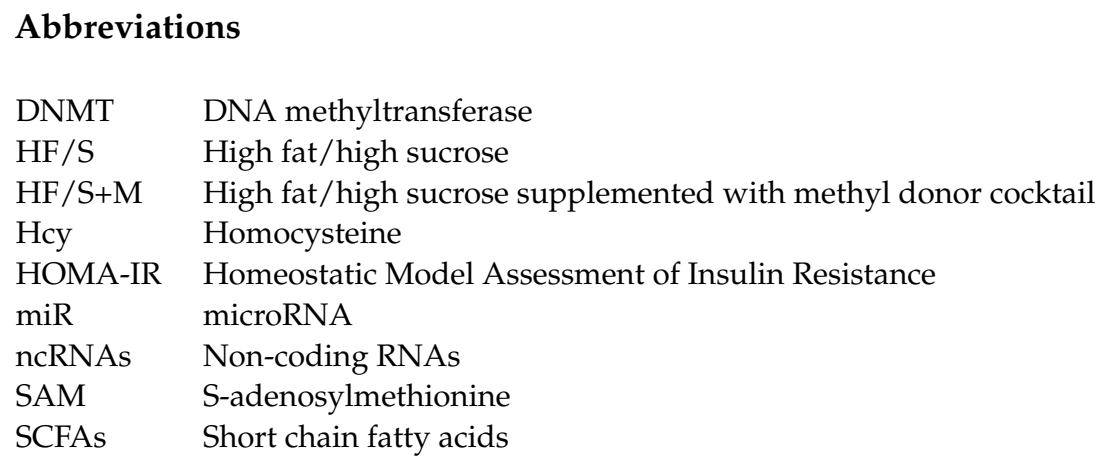

\section{References}

1. Liu, Y.; Ding, Z. Obesity, a Serious Etiologic Factor for Male Subfertility in Modern Society. Reproduction 2017, 154 , R123-R131. [CrossRef] [PubMed]

2. Giahi, L.; Mohammadmoradi, S.; Javidan, A.; Sadeghi, M.R. Nutritional Modifications in Male Infertility: A Systematic Review Covering 2 Decades. Nutr. Rev. 2016, 74, 118-130. [CrossRef] [PubMed]

3. Salas-Huetos, A.; Bulló, M.; Salas-Salvadó, J. Dietary Patterns, Foods and Nutrients in Male Fertility Parameters and Fecundability: A Systematic Review of Observational Studies. Hum. Reprod. Update 2017, 23, 371-389. [CrossRef] [PubMed]

4. Crean, A.J.; Senior, A.M. High-Fat Diets Reduce Male Reproductive Success in Animal Models: A Systematic Review and Meta-Analysis. Obes. Rev. Off. J. Int. Assoc. Study Obes. 2019, 20, 921-933. [CrossRef] [PubMed]

5. Szendroedi, J.; Roden, M. Ectopic Lipids and Organ Function. Curr. Opin. Lipidol. 2009, 20, 50-56. [CrossRef] [PubMed]

6. Stinkens, R.; Goossens, G.H.; Jocken, J.W.E.; Blaak, E.E. Targeting Fatty Acid Metabolism to Improve Glucose Metabolism. Obes. Rev. 2015, 16, 715-757. [CrossRef]

7. Campos-Silva, P.; Furriel, A.; Costa, W.S.; Sampaio, F.J.B.; Gregório, B.M.; Campos-Silva, P.; Furriel, A.; Costa, W.S.; Sampaio, F.J.B.; Gregório, B.M. Metabolic and Testicular Effects of the Long-Term Administration of Different High-Fat Diets in Adult Rats. Int. Braz. J. Urol. 2015, 41, 569-575. [CrossRef]

8. Fan, Y.; Liu, Y.; Xue, K.; Gu, G.; Fan, W.; Xu, Y.; Ding, Z. Diet-Induced Obesity in Male C57BL/6 Mice Decreases Fertility as a Consequence of Disrupted Blood-Testis Barrier. PLoS ONE 2015, 10, e0120775. [CrossRef]

9. Eacker, S.M.; Agrawal, N.; Qian, K.; Dichek, H.L.; Gong, E.-Y.; Lee, K.; Braun, R.E. Hormonal Regulation of Testicular Steroid and Cholesterol Homeostasis. Mol. Endocrinol. 2008, 22, 623-635. [CrossRef]

10. Sèdes, L.; Thirouard, L.; Maqdasy, S.; Garcia, M.; Caira, F.; Lobaccaro, J.-M.A.; Beaudoin, C.; Volle, D.H. Cholesterol: A Gatekeeper of Male Fertility? Front. Endocrinol. 2018, 9. [CrossRef]

11. Peschansky, V.J.; Wahlestedt, C. Non-Coding RNAs as Direct and Indirect Modulators of Epigenetic Regulation. Epigenetics 2014, 9, 3-12. [CrossRef] [PubMed]

12. Cescon, M.; Chianese, R.; Tavares, R.S. Environmental Impact on Male (In)Fertility via Epigenetic Route. J. Clin. Med. 2020, 9 , 2520. [CrossRef] [PubMed]

13. Papaioannou, M.D.; Nef, S. MicroRNAs in the Testis: Building up Male Fertility. J. Androl. 2010, 31, 26-33. [CrossRef] [PubMed]

14. Minatel, B.C.; Martinez, V.D.; Ng, K.W.; Sage, A.P.; Tokar, T.; Marshall, E.A.; Anderson, C.; Enfield, K.S.S.; Stewart, G.L.; Reis, P.P.; et al. Large-Scale Discovery of Previously Undetected MicroRNAs Specific to Human Liver. Hum. Genom. 2018, 12, 16. [CrossRef] [PubMed]

15. Gujar, H.; Weisenberger, D.J.; Liang, G. The Roles of Human DNA Methyltransferases and Their Isoforms in Shaping the Epigenome. Genes 2019, 10, 172. [CrossRef]

16. Mandaviya, P.R.; Stolk, L.; Heil, S.G. Homocysteine and DNA Methylation: A Review of Animal and Human Literature. Mol. Genet. Metab. 2014, 113, 243-252. [CrossRef] [PubMed]

17. Ma, X.; Kang, S. Functional Implications of DNA Methylation in Adipose Biology. Diabetes 2019, 68, 871-878. [CrossRef] [PubMed]

18. King, S.E.; Skinner, M.K. Epigenetic Transgenerational Inheritance of Obesity Susceptibility. Trends Endocrinol. Metab. 2020, 31, 478-494. [CrossRef]

19. Ducker, G.S.; Rabinowitz, J.D. One-Carbon Metabolism in Health and Disease. Cell Metab. 2017, 25, 27-42. [CrossRef]

20. Radziejewska, A.; Muzsik, A.; Milagro, F.I.; Martínez, J.A.; Chmurzynska, A. One-Carbon Metabolism and Nonalcoholic Fatty Liver Disease: The Crosstalk between Nutrients, Microbiota, and Genetics. Lifestyle Genom. 2020, 13, 53-63. [CrossRef]

21. Bjelakovic, G.; Stojanovic, I.; Stoimenov, T.J.; Pavlovic, D.; Kocic, G.; Bjelakovic, G.B.; Sokolovic, D.; Basic, J. Polyamines, Folic Acid Supplementation and Cancerogenesis. Pteridines 2017, 28, 115-131. [CrossRef]

22. Lurz, E.; Horne, R.G.; Määttänen, P.; Wu, R.Y.; Botts, S.R.; Li, B.; Rossi, L.; Johnson-Henry, K.C.; Pierro, A.; Surette, M.G.; et al Vitamin B12 Deficiency Alters the Gut Microbiota in a Murine Model of Colitis. Front. Nutr. 2020, 7. [CrossRef] [PubMed]

23. Nazki, F.H.; Sameer, A.S.; Ganaie, B.A. Folate: Metabolism, Genes, Polymorphisms and the Associated Diseases. Gene 2014, 533, 11-20. [CrossRef] [PubMed] 
24. Chiuve, S.E.; Giovannucci, E.L.; Hankinson, S.E.; Zeisel, S.H.; Dougherty, L.W.; Willett, W.C.; Rimm, E.B. The Association between Betaine and Choline Intakes and the Plasma Concentrations of Homocysteine in Women. Am. J. Clin. Nutr. 2007, 86, 1073-1081. [CrossRef] [PubMed]

25. Zeisel, S.H. Choline, Other Methyl-Donors and Epigenetics. Nutrients 2017, 9, 445. [CrossRef] [PubMed]

26. Salbaum, J.M.; Kappen, C. Genetic and Epigenomic Footprints of Folate. Prog. Mol. Biol. Transl. Sci. 2012, 108, 129-158. [CrossRef]

27. Kok, D.E.G.; Dhonukshe-Rutten, R.A.M.; Lute, C.; Heil, S.G.; Uitterlinden, A.G.; van der Velde, N.; van Meurs, J.B.J.; van Schoor, N.M.; Hooiveld, G.J.E.J.; de Groot, L.C.P.G.M.; et al. The Effects of Long-Term Daily Folic Acid and Vitamin B12 Supplementation on Genome-Wide DNA Methylation in Elderly Subjects. Clin. Epigenetics 2015, 7, 121. [CrossRef]

28. Nilsson, E.; Matte, A.; Perfilyev, A.; de Mello, V.D.; Käkelä, P.; Pihlajamäki, J.; Ling, C. Epigenetic Alterations in Human Liver From Subjects With Type 2 Diabetes in Parallel With Reduced Folate Levels. J. Clin. Endocrinol. Metab. 2015, 100, E1491-E1501. [CrossRef]

29. Ly, A.; Hoyt, L.; Crowell, J.; Kim, Y.-I. Folate and DNA Methylation. Antioxid. Redox Signal. 2012, 17, 302-326. [CrossRef]

30. Romano, K.A.; Vivas, E.I.; Amador-Noguez, D.; Rey, F.E. Intestinal Microbiota Composition Modulates Choline Bioavailability from Diet and Accumulation of the Proatherogenic Metabolite Trimethylamine-N-Oxide. mBio 2015, 6. [CrossRef]

31. Mayengbam, S.; Chleilat, F.; Reimer, R.A. Dietary Vitamin B6 Deficiency Impairs Gut Microbiota and Host and Microbial Metabolites in Rats. Biomedicines 2020, 8, 469. [CrossRef] [PubMed]

32. Kalhan, S.C. One Carbon Metabolism in Pregnancy: Impact on Maternal, Fetal and Neonatal Health. Mol. Cell. Endocrinol. 2016, 435, 48-60. [CrossRef] [PubMed]

33. Singh, K.; Jaiswal, K. One-Carbon Metabolism, Spermatogenesis, and Male Infertility. Reprod. Sci. 2013, 20, 622-630. [CrossRef] [PubMed]

34. Sujit, K.M.; Sarkar, S.; Singh, V.; Pandey, R.; Agrawal, N.K.; Trivedi, S.; Singh, K.; Gupta, G.; Rajender, S. Genome-Wide Differential Methylation Analyses Identifies Methylation Signatures of Male Infertility. Hum. Reprod. 2018, 33, $2256-2267$. [CrossRef] [PubMed]

35. Song, Y.; Yang, L. Transgenerational Impaired Spermatogenesis with Sperm H19 and Gt12 Hypomethylation Induced by the Endocrine Disruptor p, p $^{\prime}$-DDE. Toxicol. Lett. 2018, 297, 34-41. [CrossRef] [PubMed]

36. Irani, M.; Amirian, M.; Sadeghi, R.; Lez, J.L.; Roudsari, R.L. The Effect of Folate and Folate Plus Zinc Supplementation on Endocrine Parameters and Sperm Characteristics in Sub-Fertile Men: A Systematic Review and Meta-Analysis. Urol. J. 2017, 14, 4069-4078. [CrossRef] [PubMed]

37. Carlin, J.; George, R.; Reyes, T.M. Methyl Donor Supplementation Blocks the Adverse Effects of Maternal High Fat Diet on Offspring Physiology. PLoS ONE 2013, 8, e63549. [CrossRef]

38. Zeisel, S.H. Importance of Methyl Donors during Reproduction. Am. J. Clin. Nutr. 2009, 89, 673S-677S. [CrossRef]

39. Tang, M.; Xu, W.; Wang, Q.; Xiao, W.; Xu, R. Potential of DNMT and Its Epigenetic Regulation for Lung Cancer Therapy. Curr. Genom. 2009, 10, 336-352. [CrossRef]

40. Benito-Vicente, A.; Uribe, K.B.; Rotllan, N.; Ramírez, C.M.; Jebari-Benslaiman, S.; Goedeke, L.; Canfrán-Duque, A.; Galicia-García, U.; Saenz De Urturi, D.; Aspichueta, P.; et al. MiR-27b Modulates Insulin Signaling in Hepatocytes by Regulating Insulin Receptor Expression. Int. J. Mol. Sci. 2020, 21, 8675. [CrossRef]

41. Jiménez-Chillarón, J.C.; Díaz, R.; Martínez, D.; Pentinat, T.; Ramón-Krauel, M.; Ribó, S.; Plösch, T. The Role of Nutrition on Epigenetic Modifications and Their Implications on Health. Biochimie 2012, 94, 2242-2263. [CrossRef] [PubMed]

42. Cooper, R.; Hyppönen, E.; Berry, D.; Power, C. Associations between Parental and Offspring Adiposity up to Midlife: The Contribution of Adult Lifestyle Factors in the 1958 British Birth Cohort Study. Am. J. Clin. Nutr. 2010, 92, 946-953. [CrossRef] [PubMed]

43. Li, L.; Law, C.; Lo Conte, R.; Power, C. Intergenerational Influences on Childhood Body Mass Index: The Effect of Parental Body Mass Index Trajectories. Am. J. Clin. Nutr. 2009, 89, 551-557. [CrossRef] [PubMed]

44. Masuyama, H.; Mitsui, T.; Eguchi, T.; Tamada, S.; Hiramatsu, Y. The Effects of Paternal High-Fat Diet Exposure on Offspring Metabolism with Epigenetic Changes in the Mouse Adiponectin and Leptin Gene Promoters. Am. J. Physiol. Endocrinol. Metab. 2016, 311, E236-E245. [CrossRef] [PubMed]

45. Bannister, A.J.; Kouzarides, T. Regulation of Chromatin by Histone Modifications. Cell Res. 2011, 21, 381. [CrossRef] [PubMed]

46. Cedar, H.; Bergman, Y. Linking DNA Methylation and Histone Modification: Patterns and Paradigms. Nat. Rev. Genet. 2009, 10, 295-304. [CrossRef] [PubMed]

47. Pigeyre, M.; Yazdi, F.T.; Kaur, Y.; Meyre, D. Recent Progress in Genetics, Epigenetics and Metagenomics Unveils the Pathophysiology of Human Obesity. Clin. Sci. Lond. Engl. 1979 2016, 130, 943-986. [CrossRef]

48. van Dijk, S.J.; Tellam, R.L.; Morrison, J.L.; Muhlhausler, B.S.; Molloy, P.L. Recent Developments on the Role of Epigenetics in Obesity and Metabolic Disease. Clin. Epigenetics 2015, 7, 66. [CrossRef]

49. Yao, H.; Fan, C.; Lu, Y.; Fan, X.; Xia, L.; Li, P.; Wang, R.; Tang, T.; Wang, Y.; Qi, K. Alteration of Gut Microbiota Affects Expression of Adiponectin and Resistin through Modifying DNA Methylation in High-Fat Diet-Induced Obese Mice. Genes Nutr. 2020, 15, 12. [CrossRef]

50. Lu, Y.; Fan, C.; Liang, A.; Fan, X.; Wang, R.; Li, P.; Qi, K. Effects of SCFA on the DNA Methylation Pattern of Adiponectin and Resistin in High-Fat-Diet-Induced Obese Male Mice. Br. J. Nutr. 2018, 120, 385-392. [CrossRef] 
51. Elsner, V.; Cechinel, L.; de Meireles, L.F.; Bertoldi, K.; Siqueira, I. Epigenetic Marks Are Modulated by Gender and Time of the Day in the Hippocampi of Adolescent Rats: A Preliminary Study. Neural Regen. Res. 2018, 13, 2160. [CrossRef] [PubMed]

52. Maschietto, M.; Bastos, L.C.; Tahira, A.C.; Bastos, E.P.; Euclydes, V.L.V.; Brentani, A.; Fink, G.; de Baumont, A.; Felipe-Silva, A.; Francisco, R.P.V.; et al. Sex Differences in DNA Methylation of the Cord Blood Are Related to Sex-Bias Psychiatric Diseases. Sci. Rep. 2017, 7, 44547. [CrossRef] [PubMed]

53. Cheung, O.K.-W.; Cheng, A.S.-L. Gender Differences in Adipocyte Metabolism and Liver Cancer Progression. Front. Genet. 2016, 7. [CrossRef] [PubMed]

54. Paul, B.; Barnes, S.; Demark-Wahnefried, W.; Morrow, C.; Salvador, C.; Skibola, C.; Tollefsbol, T.O. Influences of Diet and the Gut Microbiome on Epigenetic Modulation in Cancer and Other Diseases. Clin. Epigenetics 2015, 7, 112. [CrossRef] [PubMed]

55. Mischke, M.; Plösch, T. The Gut Microbiota and Their Metabolites: Potential Implications for the Host Epigenome. Adv. Exp. Med. Biol. 2016, 902, 33-44. [CrossRef] [PubMed]

56. Magnúsdóttir, S.; Ravcheev, D.; de Crécy-Lagard, V.; Thiele, I. Systematic Genome Assessment of B-Vitamin Biosynthesis Suggests Co-Operation among Gut Microbes. Front. Genet. 2015, 6. [CrossRef]

57. Rowland, I.; Gibson, G.; Heinken, A.; Scott, K.; Swann, J.; Thiele, I.; Tuohy, K. Gut Microbiota Functions: Metabolism of Nutrients and Other Food Components. Eur. J. Nutr. 2018, 57, 1-24. [CrossRef]

58. Paßlack, N.; Vahjen, W.; Zentek, J. Impact of Dietary Cellobiose on the Fecal Microbiota of Horses. J. Equine Vet. Sci. 2020, 91, 103106. [CrossRef]

59. Hang, I.; Rinttila, T.; Zentek, J.; Kettunen, A.; Alaja, S.; Apajalahti, J.; Harmoinen, J.; de Vos, W.M.; Spillmann, T. Effect of High Contents of Dietary Animal-Derived Protein or Carbohydrates on Canine Faecal Microbiota. BMC Vet. Res. 2012, 8, 90. [CrossRef]

60. Rodríguez-Daza, M.-C.; Roquim, M.; Dudonné, S.; Pilon, G.; Levy, E.; Marette, A.; Roy, D.; Desjardins, Y. Berry Polyphenols and Fibers Modulate Distinct Microbial Metabolic Functions and Gut Microbiota Enterotype-Like Clustering in Obese Mice. Front. Microbiol. 2020, 11. [CrossRef]

61. Yuan, X.; Chen, R.; Zhang, Y.; Lin, X.; Yang, X. Gut Microbiota: Effect of Pubertal Status. BMC Microbiol. 2020, 20, 334. [CrossRef] [PubMed]

62. Cady, N.; Peterson, S.R.; Freedman, S.N.; Mangalam, A.K. Beyond Metabolism: The Complex Interplay Between Dietary Phytoestrogens, Gut Bacteria, and Cells of Nervous and Immune Systems. Front. Neurol. 2020, 11. [CrossRef] [PubMed]

63. Liu, Y.; Song, X.; Zhou, H.; Zhou, X.; Xia, Y.; Dong, X.; Zhong, W.; Tang, S.; Wang, L.; Wen, S.; et al. Gut Microbiome Associates With Lipid-Lowering Effect of Rosuvastatin in Vivo. Front. Microbiol. 2018, 9. [CrossRef] [PubMed]

64. Hung, Y.-H.; Kanke, M.; Kurtz, C.L.; Cubitt, R.; Bunaciu, R.P.; Miao, J.; Zhou, L.; Graham, J.L.; Hussain, M.M.; Havel, P.; et al. Acute Suppression of Insulin Resistance-Associated Hepatic MiR-29 in Vivo Improves Glycemic Control in Adult Mice. Physiol. Genom. 2019, 51, 379-389. [CrossRef] [PubMed]

65. Torres, J.-L.; Novo-Veleiro, I.; Manzanedo, L.; Alvela-Suárez, L.; Macías, R.; Laso, F.-J.; Marcos, M. Role of MicroRNAs in Alcohol-Induced Liver Disorders and Non-Alcoholic Fatty Liver Disease. World J. Gastroenterol. 2018, 24, 4104-4118. [CrossRef] [PubMed]

66. Choi, S.-E.; Fu, T.; Seok, S.; Kim, D.-H.; Yu, E.; Lee, K.-W.; Kang, Y.; Li, X.; Kemper, B.; Kemper, J.K. Elevated MicroRNA-34a in Obesity Reduces NAD+ Levels and SIRT1 Activity by Directly Targeting NAMPT. Aging Cell 2013, 12, 1062-1072. [CrossRef] [PubMed]

67. Tryndyak, V.P.; Latendresse, J.R.; Montgomery, B.; Ross, S.A.; Beland, F.A.; Rusyn, I.; Pogribny, I.P. Plasma MicroRNAs Are Sensitive Indicators of Inter-Strain Differences in the Severity of Liver Injury Induced in Mice by a Choline- and Folate-Deficient Diet. Toxicol. Appl. Pharmacol. 2012, 262, 52-59. [CrossRef]

68. Trajkovski, M.; Hausser, J.; Soutschek, J.; Bhat, B.; Akin, A.; Zavolan, M.; Heim, M.H.; Stoffel, M. MicroRNAs 103 and 107 Regulate Insulin Sensitivity. Nature 2011, 474, 649-653. [CrossRef]

69. Park, J.-H.; Ahn, J.; Kim, S.; Kwon, D.Y.; Ha, T.Y. Murine Hepatic MiRNAs Expression and Regulation of Gene Expression in Diet-Induced Obese Mice. Mol. Cells 2011, 31, 33-38. [CrossRef]

70. Zhang, M.; Tang, Y.; Tang, E.; Lu, W. MicroRNA-103 Represses Hepatic de Novo Lipogenesis and Alleviates NAFLD via Targeting FASN and SCD1. Biochem. Biophys. Res. Commun. 2020, 524, 716-722. [CrossRef]

71. Rottiers, V.; Najafi-Shoushtari, S.H.; Kristo, F.; Gurumurthy, S.; Zhong, L.; Li, Y.; Cohen, D.E.; Gerszten, R.E.; Bardeesy, N.; Mostoslavsky, R.; et al. MicroRNAs in Metabolism and Metabolic Diseases. Cold Spring Harb. Symp. Quant. Biol. 2011, 76, 225-233. [CrossRef] [PubMed]

72. Rayner, K.J.; Esau, C.C.; Hussain, F.N.; McDaniel, A.L.; Marshall, S.M.; van Gils, J.M.; Ray, T.D.; Sheedy, F.J.; Goedeke, L.; Liu, X.; et al. Inhibition of MiR-33a/b in Non-Human Primates Raises Plasma HDL and Lowers VLDL Triglycerides. Nature 2011, 478, 404-407. [CrossRef] [PubMed]

73. Dávalos, A.; Goedeke, L.; Smibert, P.; Ramírez, C.M.; Warrier, N.P.; Andreo, U.; Cirera-Salinas, D.; Rayner, K.; Suresh, U.; Pastor-Pareja, J.C.; et al. MiR-33a/b Contribute to the Regulation of Fatty Acid Metabolism and Insulin Signaling. Proc. Natl. Acad. Sci. USA 2011, 108, 9232-9237. [CrossRef] [PubMed]

74. Price, N.L.; Singh, A.K.; Rotllan, N.; Goedeke, L.; Wing, A.; Canfrán-Duque, A.; Diaz-Ruiz, A.; Araldi, E.; Baldán, Á.; Camporez, J.-P.; et al. Genetic Ablation of MiR-33 Increases Food Intake, Enhances Adipose Tissue Expansion, and Promotes Obesity and Insulin Resistance. Cell Rep. 2018, 22, 2133-2145. [CrossRef] [PubMed] 
75. Belleannée, C.; Calvo, É.; Caballero, J.; Sullivan, R. Epididymosomes Convey Different Repertoires of MicroRNAs throughout the Bovine Epididymis. Biol. Reprod. 2013, 89, 30. [CrossRef]

76. Benatti, R.O.; Melo, A.M.; Borges, F.O.; Ignacio-Souza, L.M.; Simino, L.a.P.; Milanski, M.; Velloso, L.A.; Torsoni, M.A.; Torsoni, A.S. Maternal High-Fat Diet Consumption Modulates Hepatic Lipid Metabolism and MicroRNA-122 (MiR-122) and MicroRNA-370 (MiR-370) Expression in Offspring. Br. J. Nutr. 2014, 111, 2112-2122. [CrossRef]

77. Cordero, P.; Campion, J.; Milagro, F.I.; Martinez, J.A. Transcriptomic and Epigenetic Changes in Early Liver Steatosis Associated to Obesity: Effect of Dietary Methyl Donor Supplementation. Mol. Genet. Metab. 2013, 110, 388-395. [CrossRef]

78. Cordero, P.; Gomez-Uriz, A.M.; Campion, J.; Milagro, F.I.; Martinez, J.A. Dietary Supplementation with Methyl Donors Reduces Fatty Liver and Modifies the Fatty Acid Synthase DNA Methylation Profile in Rats Fed an Obesogenic Diet. Genes Nutr. 2013, 8, 105-113. [CrossRef]

79. Cordero, P.; Milagro, F.I.; Campion, J.; Martinez, J.A. Supplementation with Methyl Donors during Lactation to High-Fat-SucroseFed Dams Protects Offspring against Liver Fat Accumulation When Consuming an Obesogenic Diet. J. Dev. Orig. Health Dis. 2014, 5, 385-395. [CrossRef]

80. Singh, B.; Saxena, A. Surrogate Markers of Insulin Resistance: A Review. World J. Diabetes 2010, 1, 36-47. [CrossRef]

81. Nicolucci, A.C.; Hume, M.P.; Martínez, I.; Mayengbam, S.; Walter, J.; Reimer, R.A. Prebiotics Reduce Body Fat and Alter Intestinal Microbiota in Children Who Are Overweight or With Obesity. Gastroenterology 2017, 153, 711-722. [CrossRef] [PubMed]

82. Nettleton, J.E.; Klancic, T.; Schick, A.; Choo, A.C.; Shearer, J.; Borgland, S.L.; Chleilat, F.; Mayengbam, S.; Reimer, R.A. Low-Dose Stevia (Rebaudioside A) Consumption Perturbs Gut Microbiota and the Mesolimbic Dopamine Reward System. Nutrients 2019, 11, 1248. [CrossRef] [PubMed]

83. Nettleton, J.E.; Cho, N.A.; Klancic, T.; Nicolucci, A.C.; Shearer, J.; Borgland, S.L.; Johnston, L.A.; Ramay, H.R.; Tuplin, E.N.; Chleilat, F.; et al. Maternal Low-Dose Aspartame and Stevia Consumption with an Obesogenic Diet Alters Metabolism, Gut Microbiota and Mesolimbic Reward System in Rat Dams and Their Offspring. Gut 2020, 69, 1807-1817. [CrossRef] [PubMed]

84. Paul, H.A.; Collins, K.H.; Bomhof, M.R.; Vogel, H.J.; Reimer, R.A. Potential Impact of Metabolic and Gut Microbial Response to Pregnancy and Lactation in Lean and Diet-Induced Obese Rats on Offspring Obesity Risk. Mol. Nutr. Food Res. $2018,62$. [CrossRef] [PubMed]

85. Paul, H.A.; Collins, K.H.; Nicolucci, A.C.; Urbanski, S.J.; Hart, D.A.; Vogel, H.J.; Reimer, R.A. Maternal Prebiotic Supplementation Reduces Fatty Liver Development in Offspring through Altered Microbial and Metabolomic Profiles in Rats. FASEB J. 2019, 33, 5153-5167. [CrossRef] [PubMed]

86. Callahan, B.J.; McMurdie, P.J.; Rosen, M.J.; Han, A.W.; Johnson, A.J.A.; Holmes, S.P. DADA2: High-Resolution Sample Inference from Illumina Amplicon Data. Nat. Methods 2016, 13, 581-583. [CrossRef]

87. McMurdie, P.J.; Holmes, S. Phyloseq: An R Package for Reproducible Interactive Analysis and Graphics of Microbiome Census Data. PLoS ONE 2013, 8, e61217. [CrossRef]

88. Segata, N.; Izard, J.; Waldron, L.; Gevers, D.; Miropolsky, L.; Garrett, W.S.; Huttenhower, C. Metagenomic Biomarker Discovery and Explanation. Genome Biol. 2011, 12, R60. [CrossRef] 